\title{
Knowledge, Attitude, and Practice Regarding Cardiovascular Diseases in Adults Attending Health Care Centers in Tehran, Iran
}

\author{
Fatemeh Koohi (iD) ${ }^{1}$ and Davood Khalili ${ }^{2,3,{ }^{*}}$ \\ ${ }^{1}$ Student Research Committee, Department of Epidemiology, School of Public Health and Safety, Shahid Beheshti University of Medical Sciences, Tehran, Iran \\ ${ }^{2}$ Prevention of Metabolic Disorders Research Center, Research Institute for Endocrine Sciences, Shahid Beheshti University of Medical Sciences, Tehran, Iran \\ ${ }^{3}$ Department of Biostatistics and Epidemiology, Research Institute for Endocrine Sciences, Shahid Beheshti University of Medical Sciences, Tehran, Iran \\ "Corresponding author: Prevention of Metabolic Disorders Research Center, Research Institute for Endocrine Sciences, Shahid Beheshti University of Medical Sciences, Tehran, \\ Iran. Email: dkhalili@endocrine.ac.ir
}

Received 2020 February 08; Revised 2020 September 01; Accepted 2020 September 13.

\begin{abstract}
Background: Studies on knowledge, attitude, and practice (KAP) can be valuable for public health to help in developing targeted educational programs and assessing the effectiveness of interventional programs.

Objectives: This study was designed to determine the level of current knowledge, attitude, and practice (KAP) regarding cardiovascular diseases (CVDs), CVD risk factors and symptoms in adults attending health care centers in Tehran province.

Methods: A cross-sectional study was performed using a self-administered questionnaire with score of $0-100$ on adults aged $>20$ years attending ten health care centers in Tehran province, Iran. Descriptive and multivariate logistic regression analyses were used in data analysis.

Results: A total of 300 adults (51.3\% females) with a mean age of $39.71 \pm 12.1$ years participated in this study. The median (IQR) score for knowledge about CVD was 91.7 (16.7); approximately 80\% of respondents' awareness was highly satisfactory and hypertension was the commonest identified risk factor followed by obesity. Furthermore, the median (IQR) score for attitude was 89 (18); $70 \%$ of respondents had a highly satisfactory attitude about CVD. Regarding physical activity and nutrition/smoking behaviors, just 10.7\% and $32 \%$ had highly satisfactory behavior, respectively. In the multivariate logistic regression analysis, attending university education and age $\geq 40$ years were independent factors of a better level of CVD knowledge; attending university education, and having a family history of chronic disease were independent factors of a better level of CVD attitude. Regarding a higher physical activity behavior, being a man, and for a better nutrition \& smoking behavior, attending university education were the only independent factors.

Conclusions: Although more than half of the current study participants had high knowledge and attitude about CVD, their behaviors is not satisfactory. Therefore, it is necessary to establish more effective educational interventions aimed at promoting positive health behaviors and explaining to the public that knowledge and action regarding the reduction of risk factors are linked to reduced CVD and mortality.
\end{abstract}

Keywords: Cardiovascular Diseases, Knowledge, Attitude, Practice

\section{Background}

Cardiovascular diseases (CVDs) are the leading cause of death globally (1). Each year, 31\% (17.9 million people) of global all-cause mortalities are from CVDs. Of these, more than 75 percent occur in low-and middle-income countries (2). It is predicted that if current trends of CVD deaths continue, the annual CVD deaths will increase to 23.3 million by 2030 (mainly from heart attacks and strokes) (3). Furthermore, CVDs are the first cause of death and DALYs in Iran, responsible for $46 \%$ of all deaths and $20 \%-23 \%$ of the burden of disease (4).

Although the rising CVD epidemic might be related to several individual and socio-environmental factors (5), its morbidity and mortality can be prevented by developing more precise population-based prevention programs, since most of its risk factors such as an unhealthy diet, lack of physical activity, smoking, obesity, hypertension, diabetes, and dyslipidemia are modifiable (6). Therefore, good knowledge about CVD risk factors will help people to decrease their risk, given that it has been indicated that knowledge about CVD and its risk factors is a prerequisite for changing the health behaviors and lifestyles of individuals $(7,8)$. Besides, knowledge of the warning signs of heart attack and stroke will lead to an earlier presentation to the hospital, resulting in better patient outcomes $(9,10)$.

Copyright (c) 2020, International Journal of Endocrinology and Metabolism. This is an open-access article distributed under the terms of the Creative Commons Attribution-NonCommercial 4.0 International License (http://creativecommons.org/licenses/by-nc/4.0/) which permits copy and redistribute the material just in noncommercial usages, provided the original work is properly cited. 
With the rising prevalence of NCDs and their risk factors, the IraPEN program that is based on the WHO Package of essential NCD interventions for primary health care (PEN) has been implemented into the primary health care centers for the Iranian population (11). The IraPEN uses a risk scoring tool to assess the 10-year CVD risk of individuals who referred to health centers, and then, self-care education is given to all (11). However, understanding the fundamental context of disease is required for reaching ideal health behavior (12) and succeeding in the prevention and control of these diseases, as this knowledge will teach individuals to be more proactive in reducing their exposure to modifiable risk factors for CVD (13).

Since studies on knowledge, attitude, and practice (KAP) increase our understanding of knowledge and behavior regarding cardiovascular health in the community (14), they can be valuable for public health to help in developing targeted educational programs (10) and assessing the effectiveness of intervention programs (15). Knowledge of CVD has been studied in various populations. Some of these studies have focused on patients $(16,17)$, and a few studies have been carried out in the general population (1821). Yet, little is known about the knowledge of CVD, its symptoms, and risk factors in Iran.

\section{Objectives}

This study was designed to determine the level of current knowledge, attitude, and practice (KAP) regarding cardiovascular diseases (CVDs), CVD risk factors and symptoms in adults attending health care centers in Tehran.

\section{Methods}

\subsection{Study Design and Participants}

This was a cross-sectional study that was conducted in Tehran province, Iran, between August and October 2018. The study population consisted of 300 adults aged $>20$ years, selected from 10 public health care centers under the supervision of Shahid Beheshti University of Medical Sciences (SBMU) in Tehran province; these centers differ culturally and socioeconomically. The sample size was calculated based on the standard deviation (SD) of the knowledge in a previous study (17) using PASS software. Considering $\alpha=0.05$ and standard deviation [SD] =3.91(17), a sample size of 238 was obtained, in which after considering a $20 \%$ dropout rate, we studied 300 participants. All participants provided verbal informed consent.

\subsection{Questionnaire}

Data were collected through a self-administered questionnaire consisting of personal questions and 29 questions related to KAP regarding CVD (CVD-KAP29). A KAP questionnaire measures the knowledge, attitude, and practice of a community regarding any given subject. Knowledge refers to a community's understanding of this subject, CVDs, risk factors, and symptoms in this case. Attitude refers to their learned predispositional thoughts, beliefs, and feelings towards this subject. Practice refers to how they act and use preventive measures towards this subject (22).

The CVD-KAP29 was developed based on the results of the literature review and interviews with five experts in health education, epidemiology, cardiovascular disease, and nutrition. Using the content validity ratio (CVR) and content validity index (CVI), the content validity of the CVD-KAP29 was established by a multidisciplinary panel of 12 experts with experience in related fields. The CVR and CVI of the questionnaire were 0.80 and 0.91 , respectively. It was also assessed for readability and comprehension of 10 individuals with different demographic characteristics; based on that, the questionnaire was simple to understand and answer. The results of the exploratory factor analysis (EFA) conducted with a four-factor solution using a varimax rotation showed that among 30 initial items, only one item (q30) had a factor loading $<0.3$, and finally, 29 items were retained. The results of confirmatory factorial analysis (CFA) also established the construct validity of the CVDKAP29 in which the root mean square error of approximation (RMSEA), comparative fit index (CFI), and the goodness of fit index (GFI) were $0.068,0.94$, and 0.83 , respectively, indicating acceptable model fit indices. Intra-class correlation coefficients indicated a good-to-excellent test-retest reliability in knowledge and attitude subscales and poor reliability in the practice subscale. Overall, Cronbach's alpha coefficients for knowledge, attitude, physical activityrelated behaviors and nutrition, and smoking behaviors subscales were $0.856,0.915,0.711$, and 0.509 , respectively, indicating a good internal consistency.

The first section of the CVD-KAP29 included 12 items to provide information about personal questions. Section 2 consisted of 12 three-point Likert scale questions that determine the knowledge of the risk factors, symptoms, and prevention of CVD. The third section included 10 five-point Likert scale questions to provide information about the subjects' attitude. Section 4 included two questions to explore the participants' physical activity behaviors. Finally, section five consisted of five questions to address their nutrition \& smoking behaviors. All scores were proportionally transformed to $0-100$. 


\subsection{Statistical Analysis}

Categorical variables are presented as frequency and percentages, and KAP scores are presented as the median and interquartile range (IQR). Total knowledge, attitude, physical and nutritional and smoking scores were classified into the following five categories based on the quintile scores: $\leq 20$, "highly insufficient"; 21 - 40, "insufficient"; 41 - 60, "sufficient"; 61 - 80, "satisfactory"; > 80, "highly satisfactory" (8). Initially, we performed univariate logistic regression to determine the relationship of the knowledge, attitude, physical activity, and nutrition and smoking of CVD with each independent variable. Then we performed a multiple logistic regression analysis, including all variables with a P value $\leq 0.3$ in the univariate analysis to determine the factors that are independently associated with CVD KAP scores. For each model, we categorized response options for the dependent variable as either "highly insufficient" or "insufficient" or "sufficient" or "satisfactory" vs. "highly satisfactory". A P $<0.05$ was considered to be statistically significant. The Statistical Package for Social Sciences (SPSS, version 21, SPSS, Chicago, IL, U.S.A.) was used for data analysis.

\section{Results}

Table 1 shows the characteristics of the participants. A total of 300 adults with a mean age of $39.71 \pm 12.1$ years (range: 21 - 74), participated in the study. Of these, 154 were female (51.3\%). The majority of participants were married (79\%); $44 \%$ of participants had a university education, and $62.7 \%$ were employed. About forty-two percent indicated having a family history of chronic diseases including CVD, hypertension, diabetes, or dyslipidemia in their immediate family members, and twenty-six percent had a self-history of chronic disease.

Table 2 shows the median (IQR) and percentage distribution of the level of knowledge, attitude, and practice/behavior regarding CVD based on the quintile scores. The median (IQR) score for knowledge about CVD was 91.7 (16.7), awareness of approximately $80 \%$ of respondents was highly satisfactory. As shown in Table 3, more than $70 \%$ of the participants were aware of the fact that CVD is the main cause of death in Iran; the commonest risk factor identified was hypertension followed by obesity, and about 70\% of the participants identified at least one CVD symptom.

Furthermore, the median (IQR) score for attitude was 89 (18); 70\% of respondents had a highly satisfactory attitude about CVD, as illustrated in Table 2. Regarding physical activity and nutrition and smoking behaviors, just 10.7\% and $32 \%$ had highly satisfactory behaviors, respectively(Table 2). Just $20 \%$ of participants exercised more than three

\begin{tabular}{|c|c|c|}
\hline Variable & Subgroups & Values \\
\hline \multirow{2}{*}{ Sex } & Male & $146(48.7)$ \\
\hline & Female & $154(51.3)$ \\
\hline \multirow{2}{*}{ Age } & $<40$ years & $179(59.7)$ \\
\hline & $\geq 40$ years & $113(39.7)$ \\
\hline \multirow{2}{*}{ Marital status } & Single ${ }^{\mathrm{b}}$ & $63(21.0)$ \\
\hline & Married & $237(79.0)$ \\
\hline \multirow{2}{*}{ Education level } & $\begin{array}{c}\text { Low-intermediate } \\
\text { education }{ }^{c}\end{array}$ & $168(56.0)$ \\
\hline & $\begin{array}{l}\text { University } \\
\text { education }\end{array}$ & $132(44.0)$ \\
\hline \multirow{2}{*}{ Occupation status } & Employed & $188(62.7)$ \\
\hline & Unemployed $^{\mathrm{d}}$ & $112(37.3)$ \\
\hline \multirow{2}{*}{ Residence } & Rural & $133(34.3)$ \\
\hline & Urban & $164(54.7)$ \\
\hline \multirow{2}{*}{ Body mass index } & $<25$ & $128(42.7)$ \\
\hline & $\geq 25$ & $169(56.3)$ \\
\hline \multirow{2}{*}{$\begin{array}{l}\text { Family history of chronic } \\
\text { diseases }^{\mathrm{e}}\end{array}$} & Yes & $162(42.1)$ \\
\hline & No & $118(57.9)$ \\
\hline \multirow{2}{*}{$\begin{array}{l}\text { Self-history of chronic } \\
\text { diseases }^{\mathrm{e}}\end{array}$} & Yes & $79(26.3)$ \\
\hline & No & $202(67.3)$ \\
\hline
\end{tabular}

${ }^{\mathrm{a}}$ Values are expressed as No. (\%).

${ }^{\mathrm{b}}$ Includes never married, divorced, and widowed.

'Includes primary school, under diploma, and diploma.

${ }^{\mathrm{d}}$ Includes retired, homemakers, and students.

${ }^{\mathrm{e}}$ Includes CVD, hypertension, diabetes, dyslipidemia

times in a week; almost $21 \%$ of participants had a healthy diet (eating 2 to 4 units of fruit and 3 to 5 units of raw or cooked vegetables in their daily diet, don't add salt to their food at the table, etc.). Nearly $20 \%$ of participants smoked regularly or sometimes.

Table 4 shows the results of the multivariate logistic regression model for participants' characteristics associated with the highly satisfactory KAP regarding CVD. In the univariate analysis, age and education were the only factors significantly associated with knowledge about CVD $(\mathrm{P}<0.05)$. Factors significantly associated with attitude regarding CVD included education and family history of chronic disease. Age was the only factor significantly associated with physical activity, and finally, education was the only factor significantly associated with nutrition and smoking behaviors. These statistically significant factors, as well as factors with a Pvalue $\leq 0.3$ in the univariate analysis, were included in the multivariate logistic regression model for each response option. According to our results, the knowledge about CVD was significantly higher among participants who aged $\geq 40$ years compared to those $<$ 


\begin{tabular}{|c|c|c|c|c|}
\hline Scores $^{\mathbf{b}}$ & Knowledge & Attitude & Physical Activity Behavior & Nutrition and Smoking Behavior \\
\hline Total score & $91.7(16.7)$ & $89(18)$ & $50(25)$ & $80(30)$ \\
\hline \multicolumn{5}{|l|}{ Quintile scores $^{\text {b }}$} \\
\hline Highly insufficient & $5(1.7)$ & - & $42(14)$ & $3(1)$ \\
\hline Insufficient & $2(0.7)$ & $4(1.3)$ & $57(19)$ & $29(9.7)$ \\
\hline Sufficient & $6(2)$ & $3(1)$ & $152(50.7)$ & $66(22)$ \\
\hline Satisfactory & $46(15.3)$ & $83(27.7)$ & $17(5.7)$ & $96(32)$ \\
\hline Highly satisfactory & $241(80.3)$ & $210(70)$ & $32(10.7)$ & $106(35.3)$ \\
\hline
\end{tabular}

${ }^{a}$ Values are expressed as No. (\%) or median (IQR).

${ }^{\mathrm{b}}$ Includes $\leq 20$, "highly insufficient"; 21 - 40, "insufficient"; 41 - 60, "sufficient"; 61 - 80, "satisfactory"; > 80, "highly satisfactory".

\begin{tabular}{lc}
\hline Table 3. Participants' Knowledge of CVD, its Risk Factors, and Symptoms $(\mathrm{N}=300)^{\mathrm{a}}$ \\
\hline Category & Values \\
\hline CVD and its risk factors & $211(70.3)$ \\
\hline CVD is a leading cause of death in Iran & $271(90.3)$ \\
\hline Physical inactivity & $282(94)$ \\
\hline Unhealthy diet & $231(77)$ \\
\hline Positive family history & $294(98)$ \\
\hline Obesity & $283(94.3)$ \\
\hline Smoking & $278(99.7)$ \\
\hline Hypertension & $238(79.3)$ \\
\hline Diabetes & \\
\hline Heart attack symptoms & $238(79.3)$ \\
\hline Chest pain or pressure or burning & $207(69)$ \\
\hline Pain or discomfort in arms, shoulder, jaw, neck or back & $212(70.7)$ \\
\hline Stroke symptoms
\end{tabular}

Abbreviation: CVD, Cardiovascular disease.

${ }^{a}$ Values are expressed as No. (\%).

40 years of age $(\mathrm{P}=0.046)$; participants who had a university education were more knowledgeable about CVD compared to those with lower education. Also, the attitude regarding CVD was significantly higher among participants who reported having a university education $(\mathrm{P}<0.001)$ and having a family history of chronic diseases $(\mathrm{P}=0.002)$ compared to those who did not. Physical activity was significantly higher among men compared to females $(\mathrm{P}=$ 0.046). Furthermore, education was the only factor independently associated with nutrition and smoking behavior (nutrition \& smoking behavior); participants who were attending university reported better nutrition \& smoking behaviors.

\section{Discussion}

This study has been done to demonstrate the current level of public knowledge, attitude, and practice regarding CVD, its risk factors, and symptoms. According to our findings, most of the participants had a highly satisfying knowledge and attitude about CVDs. This is consistent with some previous studies conducted in Shiraz, Tabriz, and Tehran provinces $(16,18,21)$. However, inconsistent with our findings, some other studies have reported a low level of knowledge in their populations $(16,18,21,23)$. In this study, respondents' knowledge regarding the CVD risk factors was better than that of the warning symptoms of heart attack and stroke, which is consistent with some other studies $(5,8)$. Hypertension was the most frequently identified risk factor of CVD, followed by smoking that was in the same line with the findings of other previous studies $(8,18,24,25)$. Although our study participants showed less knowledge related to positive family history and diabetes as risk factors, it is higher in comparison with previous studies from Kuwait, Northern Ireland, Canada, Jordan, and Nepal (8, 10, 26-28). Furthermore, the commonest CVD symptom recognized by respondents was chest pain, pressure, or burning for heart attack followed by sudden numbness or weakness of the face, arm, or leg for stroke; these findings were higher compared to that reported in Australia, Canada, and Kuwait (10, 27, 29).

The high level of knowledge and attitude about CVD among our participants might be due to the implementation of the IraPEN program in primary health care centers. IraPEN is a modification of the WHO Package of essential NCD (PEN) interventions for the Iranian population launched in 2014 by the Ministry of Health and Medical Education. IraPEN uses a risk scoring tool according to a laboratory-based WHO risk score that assesses the 10year CVD risk of individuals who referred to health centers based on various risk factors. In this system, health workers show people how to deal with their conditions, provide 


\begin{tabular}{|c|c|c|c|c|c|c|c|c|}
\hline Characteristics & $\begin{array}{l}\text { OR for Knowledge } \\
(95 \% \mathrm{CI})^{\mathrm{b}}\end{array}$ & PValue $^{c}$ & $\begin{array}{l}\text { OR for Attitude } \\
\qquad(95 \% \mathrm{CI})^{\mathbf{b}}\end{array}$ & PValue $^{c}$ & $\begin{array}{l}\text { OR for Physical } \\
\text { Activity Behavior } \\
(95 \% \mathrm{CI})^{\mathrm{b}}\end{array}$ & PValue $^{c}$ & $\begin{array}{c}\text { OR for Nutrition } \\
\text { and Smoking } \\
\text { Behavior }(95 \% \\
{\text { CI })^{\mathbf{b}}}\end{array}$ & PValue $^{c}$ \\
\hline Sex & & 0.558 & & 0.893 & & 0.046 & & 0.160 \\
\hline Male & Reference & & Reference & & Reference & & Reference & \\
\hline Female & $1.22(0.63-2.38)$ & & $1.04(0.58-1.86)$ & & $0.46(0.21-0.99)$ & & $1.47(0.86-2.51)$ & \\
\hline Age, $y$ & & 0.046 & & 0.309 & & - & & 0.337 \\
\hline$<40$ & Reference & & Reference & & - & & Reference & \\
\hline$\geq 40$ & $2.16(1.01-4.60)$ & & $1.39(0.74-2.61)$ & & - & & $1.32(0.75-2.32)$ & \\
\hline Marital status & & 0.454 & & 0.189 & & - & & 0.485 \\
\hline Single & Reference & & Reference & & - & & Reference & \\
\hline Married & $1.34(0.63-2.85)$ & & $1.59(0.80-3.18)$ & & - & & $1.27(0.65-2.47)$ & \\
\hline Education level & & 0.020 & & $<0.0001$ & & - & & 0.007 \\
\hline $\begin{array}{l}\text { Low- } \\
\text { intermediate }\end{array}$ & Reference & & Reference & & - & & Reference & \\
\hline $\begin{array}{l}\text { University } \\
\text { education }\end{array}$ & $2.24(1.13-4.43)$ & & $3.37(1.84-6.16)$ & & - & & $2.07(1.22-3.50)$ & \\
\hline $\begin{array}{l}\text { Family history of } \\
\text { chronic disease }\end{array}$ & & 0.315 & & 0.002 & & - & & 0.262 \\
\hline Yes & $1.42(0.72-2.83)$ & & $2.63(1.43-4.86)$ & & - & & $1.38(0.79-2.42)$ & \\
\hline No & Reference & & Reference & & - & & Reference & \\
\hline $\begin{array}{l}\text { Self-history of } \\
\text { chronic disease }\end{array}$ & & 0.856 & & 0.742 & . & - & & 0.194 \\
\hline Yes & $0.93(4.0-2.16)$ & & $0.88(0.42-1.45)$ & & - & & $1.54(0.80-2.95)$ & \\
\hline No & Reference & & Reference & & - & & Reference & \\
\hline
\end{tabular}

access to affordable medicine, and guidance on practicing healthy habits, like regular exercise and a healthy diet (11, 30).

Despite the high level of knowledge and attitude, almost one-fifth of our participants reported exercising more than three times a week or having a healthy diet, and nearly one-fifth are smokers.

Consistent with our findings, a review study reported that the Middle East has one of the worst physical activity profiles globally (31). Based on the result of this review, physical inactivity, especially in women, and an unhealthy diet are the most prevalent metabolic risk factors in almost all countries in this region (31).

Based on our results, higher educated individuals have significantly higher knowledge, attitude, and nutrition and smoking behaviors compared to those with low to intermediate education, similar to other studies, which observed a consistent link between better KAP scores and higher education $(8,10,24,25)$. It seems that it is reason- able to assume higher CVD KAP scores in higher educated individuals since more education can result in more exposure to information about diseases.

Besides, Similar to some previous studies, which reported a significant association between age and CVD knowledge $(23,25)$, the current study showed that participants more than 40 years old were more knowledgeable about CVD compared to those aged less than 40 years. This is in contrast to other studies, which reported no significant difference in CVD knowledge among different age groups $(23,26,28)$. This might be due to middle-aged people usually getting more medical care and having more intention to access information about diseases.

Nevertheless, the current study did not find a significant difference among females and males regarding CVD $\mathrm{KAP}$, which is consistent with other studies conducted in a different population $(8,16,26,28)$. However, this is in contrast with some other findings of previous studies, which reported a significant association between sex and CVD 
knowledge $(8,10,25)$. Also, the current findings did not find better knowledge and behavior regarding CVD in participants who reported having a positive family history of chronic disease, including CVD, hypertension, diabetes, or dyslipidemia; but their attitude was significantly better in comparison to those who did not have such a family history. Furthermore, participants who have CVD or diabetes, hypertension, and dyslipidemia did not have a higher CVD KAP score in comparison to those who did not, which is consistent with the study conducted by Awad and Al-Nafisi (10). It may be because of high knowledge in all participants that we could not find any difference.

The strength of this study is using a validated questionnaire. However, the main limitation is that participants were selected from 10 centers in only one province of Iran, which may limit the generalizability of the results, and further investigations of other Iranian populations are recommended.

\subsection{Conclusions}

This study demonstrated the current level of public knowledge, attitude, and practice regarding CVD, CVD risk factors and symptoms. Although more than half of the current study participants had high knowledge and attitude about CVD, their behavior is not satisfied. Therefore, it is necessary to establish more effective educational interventions aimed at promoting positive health behaviors and explaining to the public that knowledge and action regarding the reduction of risk factors are linked to reduced CVD and mortality.

\section{Acknowledgments}

We gratefully acknowledge Dr. Farzaneh Farbakhsh, MS. Maliheh Akbari, and Ms. Sahar Asgari for sharing their knowledge and information during the questionnaire's development and/or their contribution during data collection. We also appreciate the financial support of the " $S$ tudent Research Committee" and "Research \& Technology Chancellor" at Shahid Beheshti University of Medical Sciences for this study.

\section{Footnotes}

Authors' Contribution: FK acquisition of data, analysis, and interpretation of data, and drafting of the manuscript. DK concept and design, administrative, technical, and material support, study supervision, and critical revision of the manuscript for important intellectual content.

Conflict of Interests: The authors declare that there is no conflict of interest regarding the publication of this article.
Ethical Approval: The ethical approval code was IR.SBMU.RETECH.REC.1397.910.

Funding/Support: This study is related to the project no.: 1397/70724 from the Student Research Committee, Shahid Beheshti University of Medical Sciences, Tehran, Iran.

Informed Consent: All participants provided verbal informed consent.

\section{References}

1. Roth GA, Johnson C, Abajobir A, Abd-Allah F, Abera SF, Abyu G, et al. Global, Regional, and National Burden of Cardiovascular Diseases for 10 Causes, 1990 to 2015. J Am Coll Cardiol. 2017;70(1):1-25. doi: 10.1016/j.jacc.2017.04.052. [PubMed: 28527533]. [PubMed Central: PMC5491406].

2. WHO. Cardiovascular diseases. Geneva: World Health Organization; 2020.

3. Heidenreich PA, Trogdon JG, Khavjou OA, Butler J, Dracup K, Ezekowitz $\mathrm{MD}$, et al. Forecasting the future of cardiovascular disease in the United States: a policy statement from the American Heart Association.Circulation. 2011;123(8):933-44. doi:10.1161/CIR.0b013e31820a55f5. [PubMed: 21262990].

4. GBD Compare.2017. Available from: http://vizhub.healthdata.org/gbdcompare.

5. Sarrafzadegan N, Mohammmadifard N. Cardiovascular Disease in Iran in the Last 40 Years: Prevalence, Mortality, Morbidity, Challenges and Strategies for Cardiovascular Prevention. Arch Iran Med. 2019;22(4):204-10. [PubMed: 31126179].

6. Pearson TA, Palaniappan LP, Artinian NT, Carnethon MR, Criqui MH, Daniels SR, et al. American Heart Association Guide for Improving Cardiovascular Health at the Community Level, 2013 update: a scientific statement for public health practitioners, healthcare providers, and health policy makers. Circulation. 2013;127(16):1730-53. doi: 10.1161/CIR.ob013e31828f8a94. [PubMed: 23519758].

7. Muntner P, Woodward M, Mann DM, Shimbo D, Michos ED, Blumenthal RS, et al. Comparison of the Framingham Heart Study hypertension model with blood pressure alone in the prediction of risk of hypertension: the Multi-Ethnic Study of Atherosclerosis. Hypertension. 2010;55(6):1339-45. doi: 10.1161/HYPERTENSIONAHA.109.149609. [PubMed: 20439822]. [PubMed Central: PMC3023992].

8. Vaidya A, Aryal UR, Krettek A. Cardiovascular health knowledge, attitude and practice/behaviour in an urbanising community of Nepal: a population-based cross-sectional study from Jhaukhel-Duwakot Health Demographic Surveillance Site. BMJ Open. 2013;3(10). e002976. doi: 10.1136/bmjopen-2013-002976. [PubMed: 24157816]. [PubMed Central: PMC3808775].

9. Jafary FH, Aslam F, Mahmud H, Waheed A, Shakir M, Afzal A, et al. Cardiovascular health knowledge and behavior in patient attendants at four tertiary care hospitals in Pakistan-a cause for concern. BMC Public Health. 2005;5:124. doi:10.1186/1471-2458-5-124. [PubMed:16309553]. [PubMed Central: PMC1318493].

10. Awad A, Al-Nafisi H. Public knowledge of cardiovascular disease and its risk factors in Kuwait: a cross-sectional survey. BMC Public Health. 2014;14:1131. doi: 10.1186/1471-2458-14-1131. [PubMed: 25367768]. [PubMed Central: PMC4237772].

11. Saiari A. Guidelines for Providing Prevention and Control of NonCommunicable Diseases in Primary Health Care System, IraPEN protocol, Non-physician (midwife) pamphlet. Minist Health Med Educ. 2015.

12. Lloyd-Jones DM, Hong Y, Labarthe D, Mozaffarian D, Appel LJ, Van Horn L, et al. Defining and setting national goals for cardiovascular health promotion and disease reduction: the American Heart As- 
sociation's strategic Impact Goal through 2020 and beyond. Circulation. 2010;121(4):586-613. doi: 10.1161/CIRCULATIONAHA.109.192703. [PubMed: 20089546].

13. Aminde LN, Takah N, Ngwasiri C, Noubiap JJ, Tindong M, Dzudie A, et al. Population awareness of cardiovascular disease and its risk factors in Buea, Cameroon. BMC Public Health. 2017;17(1):545. doi: 10.1186/s12889-017-4477-3. [PubMed: 28583117]. [PubMed Central: PMC5460458].

14. Khan MS, Jafary FH, Faruqui AM, Rasool SI, Hatcher J, Chaturved $\mathrm{N}$, et al. High prevalence of lack of knowledge of symptoms of acute myocardial infarction in Pakistan and its contribution to delayed presentation to the hospital. BMC Public Health. 2007;7:284 doi: 10.1186/1471-2458-7-284. [PubMed: 17922923]. [PubMed Central: PMC2151942].

15. Hiew CC, Chin YS, Chan YM, Mohd Nasir MT. Development and Validation of Knowledge, Attitude and Practice on Healthy Lifestyle Questionnaire (KAP-HLQ) for Malaysian Adolescents. J Nutr Health Sci. 2015;2(4). doi: 10.15744/2393-9060.2.407.

16. Ranjbar H, Ebrahimi F, Mehrabi E. Cardiovascular disease knowl edge among cardiac rehabilitation patients in Eastern Iran: A crosssectional study. Int Cardiovasc Res J. 2018;12(2):64-8.

17. Mazloomy SS, Baghianimoghadam MH, Ehrampoush MH, Baghianimoghadam B, Mazidi M, Mozayan MR. A study of the knowledge, attitudes, and practices (KAP) of the women referred to health centers for cardiovascular disease (CVDs) and their risk factors. Health Care Women Int. 2014;35(1):50-9. doi: 10.1080/07399332.2012.755980. [PubMed: 23638684]

18. Borhani Haghighi A, Karimi AA, Amiri A, Ghaffarpasand F. Knowledge and attitude towards stroke risk factors, warning symptoms and treatment in an Iranian population. Med Princ Pract. 2010;19(6):46872. doi: 10.1159/000320306. [PubMed: 20881415].

19. Hosseininezhad M, Ebrahimi H, Seyedsaadat SM, Bakhshayesh B, Asadi M, Ghayeghran AR. Awareness toward stroke in a populationbased sample of Iranian adults. Iran J Neurol. 2017;16(1):7-14. [PubMed 28717428]. [PubMed Central: PMC5506760].

20. Ebrahimi-Mameghani M, Toupchian O, Naimi AF, Nurmohammadi M. Women's knowledge and attitude toward cardiovascular diseases risk factors and its relation with obesity and biochemical factors. Med J Tabriz Univ Med Sci Health Serv. 2011;33(2):7-12.

21. Salahshoori A, Nasirzadeh M, Haruni J, Pourhaji F, Salahshoori S,
Nozarpoor J. The Knowledge, Attitude, and Practice (KAP) of Women Health Services Staff About Risk Factors of Cardiovascular Disease (CVDs) in City of Fereydan and Chadegan. JundishapurJChron Dis Care. 2015;4(1). doi: 10.5812/jjcdc.26599.

22. Kaliyaperumal K. Guideline for conducting a knowledge, attitude and practice (KAP) study. AECS Illumination. 2004;4(1):7-9.

23. Ibrahim M, Rahman N, Haque M. Knowledge, Attitude and Practice of Malaysian Public University Students on Risk Factors for Cardiovascular Diseases. J Appl Pharm Sci. 2016:56-63. doi:10.7324/japs.2016.60208.

24. Chen W, Yu Y, Glaser K. The knowledge and attitudes of coronary heart disease prevention among middle and older aged people in a community in Taipei. Taiwan Geriatr Gerontol. 2009;4:251-62.

25. Attarchi M, Mohammadi S, Nojomi M, Labbafinejad Y. Knowledge and practice assessment of workers in a pharmaceutical company about prevention of coronary artery disease. Acta Med Iran. 2012:697-703.

26. Al Hamarneh YN, Crealey GE, McElnay JC. Coronary heart disease: health knowledge and behaviour. Int JClin Pharm. 2011;33(1):111-23. doi: 10.1007/s11096-010-9467-9. [PubMed: 21365403].

27. Gill R, Chow CM. Knowledge of heart disease and stroke among cardiology inpatients and outpatients in a Canadian innercity urban hospital. Can J Cardiol. 2010;26(10):537-40. doi: 10.1016/s0828-282x(10)70468-2. [PubMed: 21165363]. [PubMed Central: PMC3006102]

28. Mukattash TL, Shara M, Jarab AS, Al-Azzam SI, Almaaytah A, Al Hamarneh YN. Public knowledge and awareness of cardiovascular disease and its risk factors: a cross-sectional study of 1000 Jordanians. Int J Pharm Pract. 2012;20(6):367-76. doi: 10.1111/j.20427174.2012.00208.x. [PubMed: 23134095].

29. Sug Yoon S, Heller RF, Levi C, Wiggers J, Fitzgerald PE. Knowledge of stroke risk factors, warning symptoms, and treatment among an Australian urban population. Stroke. 2001;32(8):1926-30. doi: 10.1161/01.str.32.8.1926. [PubMed: 11486127].

30. Hammerich A. How are countries dealing with their current cardiovascular disease burden? A snapshot from the WHO Eastern Mediterranean Region (EMR). Glob Cardiol Sci Pract. 2018;2018(1):1. doi: 10.21542/gcsp.2018.1. [PubMed: 29644228]. [PubMed Central: PMC5857060]

31. Azizi F, Hadaegh F, Hosseinpanah F, Mirmiran P, Amouzegar A, Abdi $\mathrm{H}$, et al. Metabolic health in the Middle East and north Africa. Lancet Diabetes Endocrinol. 2019;7(11):866-79. doi:10.1016/s2213-8587(19)301792 